\title{
Association of polymorphisms in the Interleukin 23 receptor gene with osteonecrosis of femoral head in Korean population
}

\author{
Tae-Ho Kim ${ }^{1,2}$, Jung Min Hong ${ }^{1}$, Bermseok $\mathrm{Oh}^{5}$, \\ Yoon Shin $\mathrm{Cho}^{5}$, Jong-Young Lee, \\ Hyung-Lae Kim ${ }^{5}$, Jong-Eun Lee ${ }^{6}$, Mi-Hyun $\mathrm{Ha}^{1}$, \\ Eui Kyun Park ${ }^{1,4}$ and Shin-Yoon Kim ${ }^{1,3,7}$ \\ ${ }^{1}$ Skeletal Diseases Genome Research Center \\ Kyungpook National University Hospital \\ Daegu 700-412, Korea \\ ${ }^{2}$ Department of Medicine \\ ${ }^{3}$ Department of Orthopedic Surgery \\ Kyungpook National University School of Medicine \\ Daegu 700-412, Korea \\ ${ }^{4}$ Department of Pathology and Regenerative Medicine \\ School of Dentistry, Kyungpook National University \\ Daegu 700-412, Korea \\ ${ }^{5}$ National Genome Research Institute \\ National Institute of Health \\ Seoul 122-701, Korea \\ ${ }^{6}$ DNA Link, Inc. \\ Seoul 120-110, Korea \\ ${ }^{7}$ Corresponding author: Tel, 82-53-420-5635; \\ Fax, 82-53-420-5453; E-mail, syukim @ knu.ac.kr \\ DOI 10.3858/emm.2008.40.4.418
}

\section{Accepted 24 April 2008}

Abbreviations: $\mathrm{Cl}$, confidence interval; IL23R, interleukin 23 receptor; $\mathrm{LD}$, linkage disequilibrium; ON, osteonecrosis; ONFH, osteonecrosis of the femoral head; OR, odd ratio; SNP, single nucleotide polymorphism

\footnotetext{
Abstract

Osteonecrosis of the femoral head (ONFH) is known as death of the cellular portion of the femoral head due to an interruption in the vascular supply. The underlying pathophysiology regarding bone cell death remains uncertain. Recently, several studies have shown that autoimmune disorders were related to the development of osteonecrosis. This study investigated the genetic effects of Interleukin 23 receptor (IL23R) polymorphisms regarding the risk of ONFH. Ten SNPs were selected and genotyped in $\mathbf{4 4 3}$ ONFH patients and 273 control subjects in order to perform the genetic association analysis. It was found that polymorphisms of the IL23R gene (rs4655686, rs1569922 and rs7539625) were significantly associated with an increased risk of
}

ONFH ( $P$ values; 0.0198-0.0447, OR; 1.30-1.49). Particularly, a stratified analysis based on etiology (alcohol, steroid or idiopathic) showed that the associations between these polymorphisms and ONFH were most significant in idiopathic ONFH patients $(P$ values; $0.0001-0.0150$, OR; 1.45-2.17). These results suggest that IL23R polymorphisms may play an important role in the development of ONFH.

Keywords: femur head; interleukin-23; osteonecrosis; polymorphism, single nucleotide

\section{Introduction}

Osteonecrosis of the femoral head (ONFH) is a devastating disease that frequently leads to the progressive collapse of the femoral head, followed by degenerative arthritis of the hip joint. Nontraumatic ONFH has been associated with various factors such as corticosteroid usage, alcoholism, infections, marrow infiltrating diseases, coagulation defects, and some autoimmune diseases (Mont et al., 1998; Jones, 1999; Glueck et al., 2003; Boss et al., 2004; Childs, 2005). Among several confounding pathogenic mechanisms regarding ONFH, a vascular hypothesis appears to be the most persuasive, presuming that a decrease in the local blood flow in the femoral head plays a pivotal role in the pathogenesis of ONFH (de Camargo et al., 1984; Kerachian et al., 2006).

Particularly, some autoimmune disorders, including systemic lupus erythematosus (SLE), polymyalgia rheumatica (PMR), rheumatoid arthritis (RA), and inflammatory bowel disease (IBD), are related to the development of osteonecrosis (Migliaresi et al., 1994; Abu-Shakra et al., 2003; Boss et al., 2004; Tektonidou and Moutsopoulos, 2004; Lane, 2006). These diseases cause enough vasculature defects to cause a loss of microvascular flow to intraosseous tissue (Tektonidou and Moutsopoulos, 2004; Childs, 2005). Several studies reported that immunologic factors such as interleukins and TNFs might influence the development of osteonecrosis (Mont et al., 1998; Boss et al., 2004; Tektonidou and Moutsopoulos, 2004; Weitzmann and Pacifici, 2005; Sato and Takayanagi, 2006).

IL23 is a proinflammatory cytokine and consists of a $p 19$ subunit and a p40 subunit of IL12. IL23R pairs with IL12R and both are necessary for IL23 
signal pathway. IL23 regulates the activity of an immune response and promotes inflammation through the engagement of IL23R. These cytokines are primarily expressed in immune system cells such as a T cell, macrophage, and dendritic cell (Oppmann et al., 2000; Parham et al., 2002). Recently, it has been reported that IL23 deficient mice were resistant to collagen-induced arthritis (Murphy et al., 2003; Sanchez et al., 2007) and IL23 also inhibited osteoclastogenesis by RANKL (Receptor Activator for Nuclear Factor $\kappa \mathrm{B}$ Ligand) through T cell activation (Kamiya et al., 2007).

Recently, many studies have reported that IL23R was related to inflammatory disorders. Several variations of the IL23R gene have been reported to influence the risk of a developing skin disorder called psoriasis (Capon et al., 2007; Cargill et al., 2007). Also, polymorphisms of the IL23R gene were associated with susceptibility to IBD and Crohn's disease (CD) in the genome wide association studies previously published (Cardon, 2006; Duerr et al., 2006; Raelson et al., 2007). In order to determine whether polymorphisms of the IL23R gene are associated with the susceptibility of ONFH, the genotype and allele frequencies between ONFH patients and controls were compared in this study.

\section{Materials and Methods}

\section{Subjects}

The study population was comprised of 443 unrelated patients (366 men, 77 women; mean age: $49.7 \pm$
13.3) with ONFH and 273 (206 men, 67 women; mean age: $52.1 \pm 10.6)$ unrelated control subjects consecutively enrolled at the Kyungpook National University Hospital (Daegu, Korea) from 2002 to 2006. Patients were diagnosed and subgrouped by criteria which were described previously (Kim et al., 2007). Briefly, patients were subgrouped, according to etiological factors, into osteonecrosis, idiopathic (181 cases), steroid-induced (56 cases), and alcohol-induced (206 cases) groups. The control subjects were defined by the following criteria: those having no hip pain and others whose anteroposterior and frog leg lateral pelvic radiographs did not show any lesions, or with a sclerotic margin or subchondral collapse consistent with ONFH. We excluded all persons related to patients from our control group. This study was approved by the Institutional Review Board of Kyungpook National University Hospital, and all subjects gave written informed consent.

\section{Selection of SNP and genotyping}

Genomic DNA was isolated from peripheral blood of each individual by using a FlexiGene DNA Kit (QIAGEN, Valencia, CA). A total of 10 polymorphic sites regarding IL23R were selected by considering their location, allele frequencies and relevance to diseases based on public databases (dbSNP; http://www.ncbi.nlm.nih.gov/SNP/, HAP. MAP; http:// www.hapmap.org/index.html.en). The genotype identification was performed by using a Taqman probe (Applied Biosystems, Foster city,

Table 1. Frequencies of IL23R gene polymorphisms in ONFH patients and normal controls.

\begin{tabular}{|c|c|c|c|c|c|c|c|c|c|}
\hline \multirow{3}{*}{$\begin{array}{l}\text { dbSNP ID } \\
\text { rs4655686 }\end{array}$} & \multirow{3}{*}{$\begin{array}{l}\text { Position } \\
\text { Intron } 3\end{array}$} & \multirow{2}{*}{\multicolumn{4}{|c|}{ Genotype }} & \multirow{3}{*}{ Frequency $^{a}$} & \multirow{3}{*}{ Heterozygosity } & \multicolumn{2}{|c|}{$\mathrm{HWE}^{\mathrm{b}}$} \\
\hline & & & & & & & & \multirow[t]{2}{*}{ case } & \multirow[t]{2}{*}{ control } \\
\hline & & TT & AT & AA & $\mathrm{N}$ & & & & \\
\hline rs1569922 & Intron 4 & $\begin{array}{l}284 \\
\text { CC }\end{array}$ & $\begin{array}{l}340 \\
\mathrm{CT}\end{array}$ & $\begin{array}{l}76 \\
\mathrm{TT}\end{array}$ & $\begin{array}{l}700 \\
\mathrm{~N}\end{array}$ & 0.351 & 0.456 & 0.304 & 0.158 \\
\hline rs7539625 & Intron 6 & $\begin{array}{l}216 \\
\text { AA }\end{array}$ & $\begin{array}{l}368 \\
A G\end{array}$ & $\begin{array}{l}107 \\
\text { GG }\end{array}$ & $\begin{array}{l}691 \\
\mathrm{~N}\end{array}$ & 0.421 & 0.488 & 0.030 & 0.246 \\
\hline \multirow[t]{2}{*}{ rs7518660 } & Intron 7 & $\begin{array}{l}185 \\
\text { GG }\end{array}$ & $\begin{array}{l}372 \\
\text { GA }\end{array}$ & $\begin{array}{l}148 \\
\text { AA }\end{array}$ & $\begin{array}{l}705 \\
\mathrm{~N}\end{array}$ & 0.474 & 0.499 & 0.290 & 0.257 \\
\hline & Intron 8 & $\begin{array}{l}370 \\
\text { TT }\end{array}$ & $\begin{array}{l}283 \\
\mathrm{CT}\end{array}$ & $\begin{array}{l}58 \\
\mathrm{CC}\end{array}$ & $\begin{array}{l}711 \\
\mathrm{~N}\end{array}$ & 0.281 & 0.404 & 0.490 & 0.879 \\
\hline rs10789229 & Intron 9 & $\begin{array}{l}605 \\
\mathrm{CC}\end{array}$ & $\begin{array}{l}105 \\
\text { CG }\end{array}$ & $\begin{array}{l}5 \\
\text { GG }\end{array}$ & $\begin{array}{l}715 \\
\mathrm{~N}\end{array}$ & 0.080 & 0.148 & 1.000 & 0.664 \\
\hline rs1008193 & Intron 9 & $\begin{array}{l}625 \\
C C\end{array}$ & $\begin{array}{l}85 \\
\mathrm{CT}\end{array}$ & $\begin{array}{l}4 \\
\text { TT }\end{array}$ & $\begin{array}{l}714 \\
\mathrm{~N}\end{array}$ & 0.065 & 0.122 & 1.000 & 0.256 \\
\hline rs6693831 & & 425 & 240 & 45 & 710 & 0.232 & 0.357 & 0.697 & 0.078 \\
\hline
\end{tabular}

\footnotetext{
${ }^{\mathrm{a}}$ Frequencies of rare alleles. ${ }^{\mathrm{b}} \mathrm{P}$ values of deviation from Hardy-Weinberg equilibrium among ONFH patients and control.
} 


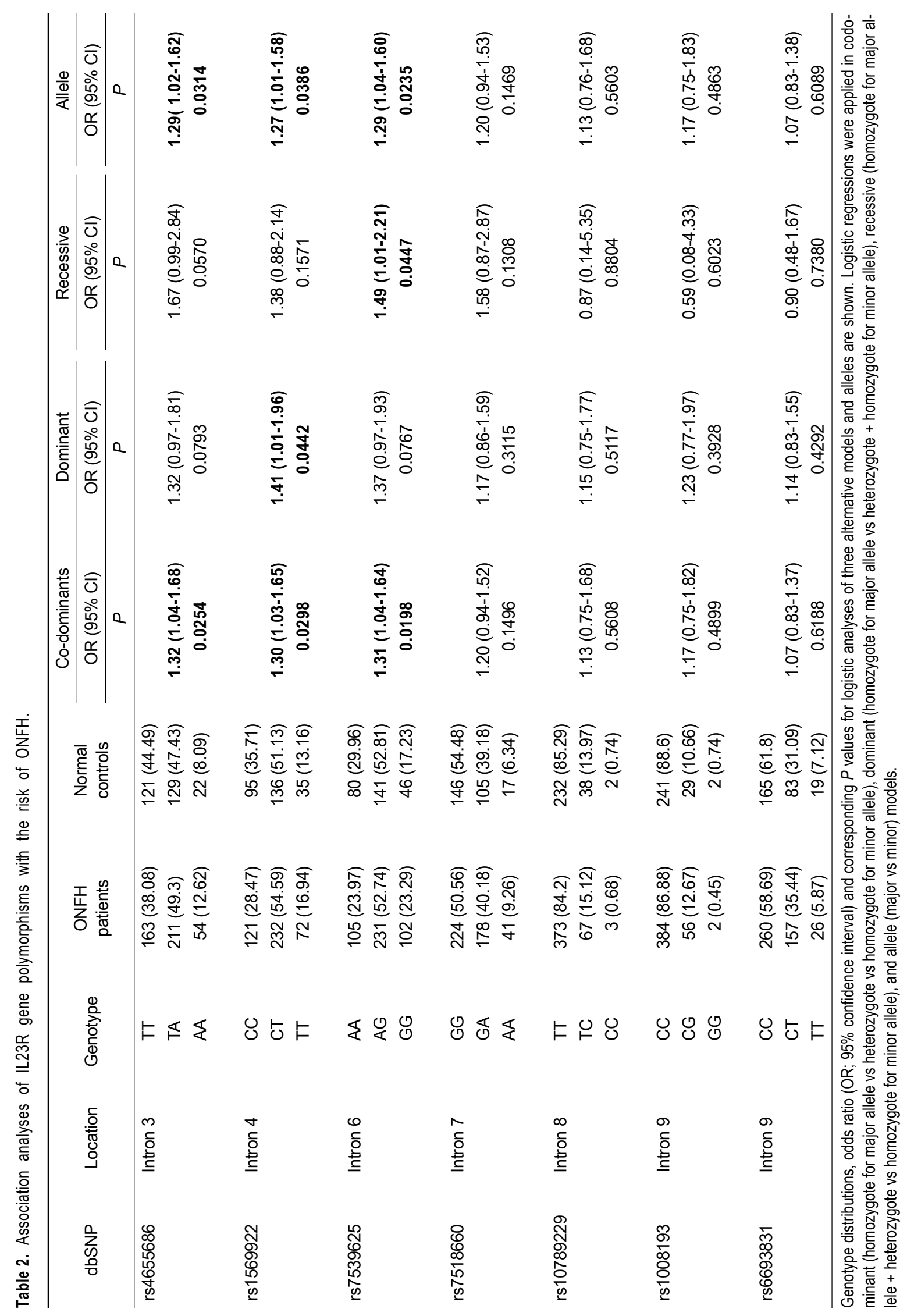




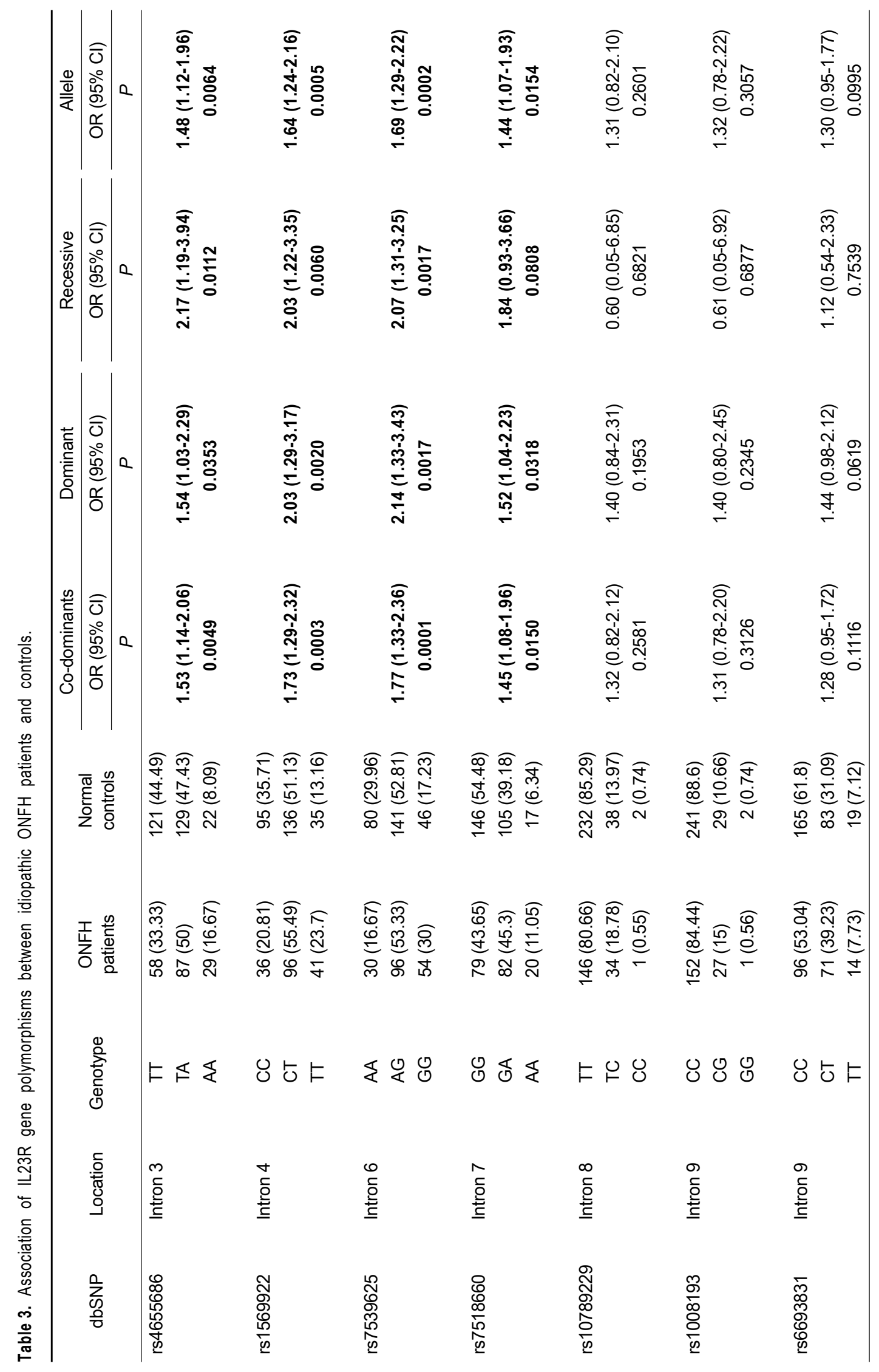


CA), according to the manufacturer's instructions. Primer Express (Applied Biosystems) was used in order to design both the PCR primers and the MGB TaqMan probes. One allelic probe was labeled with the FAM dye and the other was labeled with fluorescent VIC dye. Detailed procedures regarding the $\mathrm{PCR}$ reaction for Taqman assay have been described previously (Kim et al., 2006). Fluorescence data files from each plate were collected and analyzed by using automated allelecalling software (SDS 2.2, Applied Biosystems).

\section{Statistical analyses}

Chi-square tests were used in order to determine whether individual variants were in intra-locus equilibrium in the samples (Hardy-Weinberg equilibrium). Logistic regression analyses were used to calculate the odds ratios (OR), 95\% confidence intervals $(\mathrm{Cl})$ and corresponding $P$ values of each SNP and haplotypes controlling for age and sex as covariates with three alternative models (codominant, dominant and recessive). The linkage disequilibrium (LD) between loci was measured by using the absolute value of Lewontin's D' (|D'|) (Hedrick, 1987). Haplotype structures and their frequencies were estimated from genotyped data within the LD block by using the Haploview 3.32 (http://www.broad.mit. edu/mpg/haploview/), which estimates haplotype by an accelerated EM algorithm similar to the

A

LDs and LD block among IL23R polymorphisms

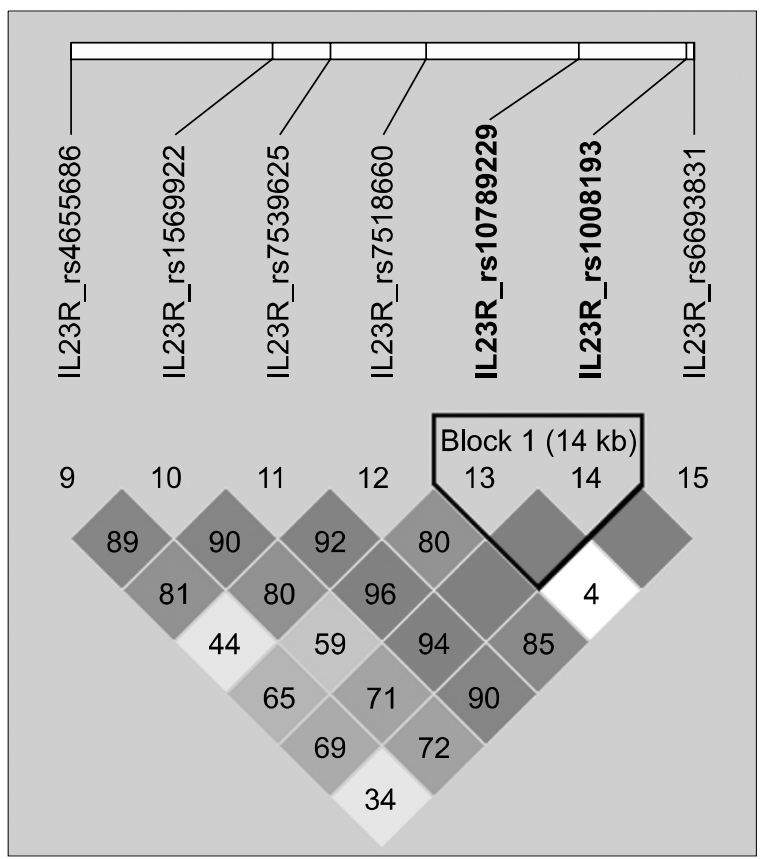

partition ligation method (Qin et al., 2002). All analyses were two-tailed and a $P$-value of $<0.05$ was considered to be statistically significant. Statistical analyses were performed by using SAS 9.1 (SAS Institute Inc., Cary, NC).

\section{Results}

In order to investigate the association of IL23R gene polymorphisms with respect to ONFH, ten polymorphic sites in the IL23R gene were genotyped regarding $443 \mathrm{ONFH}$ patients and 273 control subjects. Among the 10 SNPs genotyped, three SNP sites did not fulfill our criteria in a call rate $(\mathrm{CR})>0.90$, minor allele frequency $(\mathrm{MAF})>0.05$ and Hardy-Weinberg equilibrium (HWE) $>0.05$. Seven SNP sites were in the $\operatorname{HWE}(P>0.05)$ (Table 1). The $P$ values of each polymorphism were obtained using logistic regression analyses by comparison between ONFH patients and the controls. It was found that rs4655686, rs1569922 and rs7539625 polymorphisms of the IL23R gene were significantly associated with the risk of ONFH in an alternative analysis model ( $P$ values; 0.0198-0.0447, OR; 1.30-1.49) (Table 2). These results suggested that the minor allele of rs4655686, rs1569922 and rs7539625 (A, T and G, respectively) contributes to an increase in the risk of ONFH.

B

\begin{tabular}{|c|c|c|c|}
\hline \multicolumn{4}{|c|}{ Haplotypes in IL23R } \\
\hline Haplotypes & 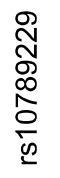 & $\begin{array}{l}\frac{m}{5} \\
\infty \\
\frac{0}{0} \\
\frac{0}{2}\end{array}$ & Frequency \\
\hline IL23R-ht1 & $\mathrm{T}$ & C & 0.918 \\
\hline IL23R-ht2 & C & G & 0.065 \\
\hline IL23R-ht3 & C & $\mathrm{C}$ & 0.016 \\
\hline
\end{tabular}

Figure 1. Linkage disequilibrium coefficients and haplotypes of IL23R (A) Linkage disequilibrium coefficients (|D'|) and LD block among IL23R polymorphisms. (B) Haplotypes of IL23R 
Further analysis based on pathological etiology (alcohol-, steroid- or idiopathic) showed that the genotypes of rs4655686, rs1569922, rs7539625 and rs7518660 of IL23R gene were specifically associated with the risk of ONFH in the idiopathic ONFH subgroup in all alternative models $(P$ values; 0.0001-0.0150, OR; 1.45-2.17) (Table 3). These results suggested that the IL23R polymorphisms were possibly important risk factors in the idiopathic ONFH. However, there was no significant association with regard to alcohol- and steroidinduced subgroups (data not shown).

Since the LD pattern has been hypothesized to be highly structured as conserved blocks of sequence separated by hotspots of recombination, the final function of a conserved haplotype may be the result of interaction among polymorphisms within the block. LD coefficients (|D'|) between all SNP pairs were calculated, and complete LD (i.e. $D^{\prime}=1$ ) were found between the rs10789229 and rs1008193 (Figure 1A). Additionally, we calculated the haplotype frequencies with two loci (rs10789229, rs1008193) within the LD block, and tested for a haplotype association between the controls and ONFH patients. Two major haplotypes among three haplotypes explained more than $98 \%$ of the variation (Figure 1B). As shown in Table 4, haplotypes were not associated with susceptibility to ONFH. In addition, haplotype analysis in subgroup patients also showed no association with the risk of ONFH (data not shown).

\section{Discussion}

ONFH is a devastating disease that frequently leads to a progressive collapse of the femoral head, followed by degenerative arthritis of the hip joint. The precise pathophysiology of ONFH is not known, but it has been suggested that a common pathogenesis of ONFH involves an interruption of the circulation of blood to the anterior-superiorlateral region of the femoral head (Atsumi and Kuroki, 1992). A previous study reported that idiopathic ONFH coincided with an increased release of a VEGF and proinflammatory factors (Boss et al., 2004). These factors include the recruitment of endothelial progenitor cells, macrophages, osteoclasts, fibroblasts, and osteoblasts, which, pervading throughout the necrotic areas, initiate the reparative processes. The bone effect resulting from systemic inflammation may lead to a variety of bone diseases including RA, osteoporosis and osteonecrosis (Migliaresi et al., 1994; Abu-Shakra et al., 2003; Lane, 2006). According to a previous report (Tektonidou and Moutsopoulos, 2004),

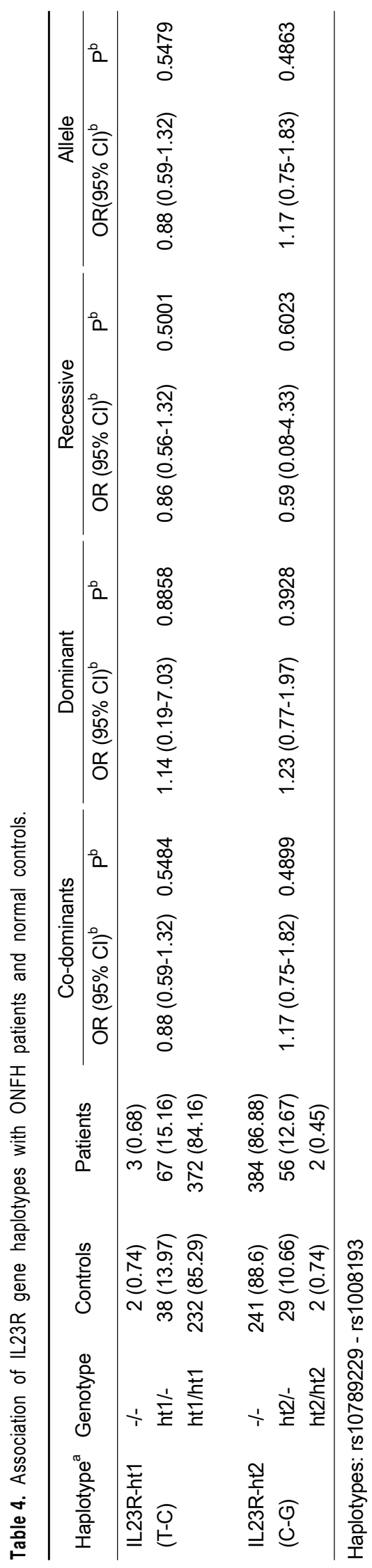


immunologic factors may be related with pathogenesis of osteonecrosis.

Cytokines are recognized as being involved in the bone metabolism process. IL3, IL6, and IL11 may act to increase the proliferation as well as the differentiation of osteoclast precursors (Goldring and Goldring, 1996; Mont et al., 1998). A previous study had suggested that IL23, an IL6/IL12 cytokine member, was related to collagen-induced arthritis in mouse models and also inhibited osteoclast formation (Murphy et al., 2003; Kamiya et al., 2007). IL4 and IFN- $\gamma$, induced by IL23, have been shown to block osteoclastogenesis by means of inhibition of the transcription factors NFATc1 and c-Fos, and induction of TNF receptor-associated factor 6 (TRAF6) (Mundy, 1996; Takayanagi et al., 2002; Moreno et al., 2003; Kamel Mohamed et al., 2005; Gao et al., 2007). Therefore, these cytokines may represent a major target for the prevention of inflammation related bone diseases and promote bone metabolism. A genome wide association study has shown that the IL23R gene was associated with autoimmune diseases, including IBD, CD and psoriasis (Cardon, 2006; Duerr et al., 2006; Raelson et al., 2007). The association between IL23R and these diseases has been replicated in many other studies with different populations (Cargill et al., 2007; Cummings et al., 2007; Dubinsky et al., 2007; Glas et al., 2007; Rioux et al., 2007; Roberts et al., 2007). The recent findings of the association studies suggested that the IL-23/IL-23R cytokine receptor system is also involved in the pathogenesis of several diseases.

In this study, we have tried to determine the contribution of IL23R gene polymorphisms in regards to ONFH. We found that polymorphisms of the IL23R gene were significantly associated with ONFH in the Korean population. In particular, the genotypes of rs4655686, rs1569922, rs7539625 and rs7518660 of the IL23R gene were specifically associated with the risk of ONFH in the idiopathic subgroup (Table 3 ). These results suggested that inflammatory factors might be one of the important risk factors in regards to idiopathic ONFH. However, there were no significant associations shown in both alcohol- and steroid-induced subgroups. No association with ONFH in these subgroups could be attributable to different etiological characteristics of subgroup patients. Corticosteroid therapy and alcoholism, which can change fat metabolism, and accumulating cell stress, which causes occlusion of the blood flow, were major risk factors with respect to osteonecrosis (Gold and Cangemi, 1979; Asano et al., 2003). In addition, alcohol and steroids promote the generation of reactive oxygen species (ROS), resulting in oxidative stress. Therefore, it was generally thought that the effect of alcohol abuse or excessive steroid administration was stronger than genetic factors in regards to alcohol- and steroid-induced ONFH patients. On the other hand, genetic factors may be more strongly related to ONFH among idiopathic patients due to no obvious reasons having been identified.

Our study had several concerns. Firstly, since our hospital is a tertiary institution covering the Daegu-Kyungpook region, more severely ill patients are usually referred to our hospital, thus possibly resulting in selection bias. Secondly, patients in the early stage of osteonecrosis might have been included in the control group since only patients were identified by a MRI and we did not check the MRI results of the control group. The numbers of controls were less than numbers of cases since the age and sex-matched normal controls were difficult to obtain. Thirdly, the incidence of ONFH in Korea is relatively higher and sex-biased (male: female $=4: 1$ ) in comparison to other populations. The majority of osteonecrosis in Korea is either idiopathic or related to excessive alcohol use. Most male patients represent alcohol-induced cases, whereas female patients represent idiopathic or steroid-induced cases. These facts suggested that the etiology of ONFH may be quite complex and possibly attributable to gender and ethnic differences.

ONFH is one of the most common diseases of the hip in Korea, responsible for more than half of the underlying causes of total hip arthroplasty. Therefore, early diagnosis of the disease using several noted genetic markers will provide beneficial information regarding individual susceptibility to ONFH and may also help high-risk individuals to take precautions against further aggravating symptoms. In conclusion, the present study suggests, for the first time, to our knowledge, that the polymorphisms of the IL23R gene are likely to be associated with the risk of ONFH, at least in the Korean population. Further replication studies in a large cohort would be needed to confirm the suggested association.

\section{Acknowledgements}

This work was supported by a grant from the Korea Health 21 R\&D Project, Ministry of Health and Welfare, Republic of Korea (Project No.: A010252), and intramural grants from the Korea National Institute of Health, Korea Center for Disease Control, Republic of Korea. 


\section{References}

Abu-Shakra M, Buskila D, Shoenfeld Y. Osteonecrosis in patients with SLE. Clin Rev Allergy Immunol 2003;25:13-24

Asano T, Takahashi KA, Fujioka M, Inoue S, Satomi Y, Nishino H, Tanaka T, Hirota Y, Takaoka K, Nakajima S, Kubo T. Genetic analysis of steroid-induced osteonecrosis of the femoral head. J Orthop Sci 2003;8:329-33

Atsumi T, Kuroki Y. Role of impairment of blood supply of the femoral head in the pathogenesis of idiopathic osteonecrosis. Clin Orthop Relat Res 1992;277:22-30

Boss JH, Misselevich I, Bejar J, Norman D, Zinman C, Reis DN. Experimentally gained insight - based proposal apropos the treatment of osteonecrosis of the femoral head. Med Hypotheses 2004;62:958-65

Capon F, Di Meglio P, Szaub J, Prescott NJ, Dunster C, Baumber L, Timms K, Gutin A, Abkevic V, Burden AD, et al. Sequence variants in the genes for the interleukin-23 receptor (IL23R) and its ligand (IL12B) confer protection against psoriasis. Hum Genet 2007;122:201-6

Cardon LR. Genetics. Delivering new disease genes. Science 2006;314:1403-5

Cargill M, Schrodi SJ, Chang M, Garcia VE, Brandon R, Callis KP, Matsunami N, Ardlie KG, Civello D, Catanese JJ, et al. A large-scale genetic association study confirms IL12B and leads to the identification of IL23R as psoriasis-risk genes. Am J Hum Genet 2007;80:273-90

Childs SG. Osteonecrosis: death of bone cells. Orthop Nurs 2005;24:295-301; quiz 302-3

Cummings JR, Ahmad T, Geremia A, Beckly J, Cooney R, Hancock L, Pathan S, Guo C, Cardon LR, Jewell DP. Contribution of the novel inflammatory bowel disease gene IL23R to disease susceptibility and phenotype. Inflamm Bowel Dis 2007;13:1063-8

de Camargo FP, de Godoy RM Jr, Tovo R. Angiography in Perthes' disease. Clin Orthop Relat Res 1984;191:216-20

Dubinsky MC, Wang D, Picornell Y, Wrobel I, Katzir L, Quiros A, Dutridge D, Wahbeh G, Silber G, Bahar R, et al. IL-23 receptor (IL-23R) gene protects against pediatric Crohn's disease. Inflamm Bowel Dis 2007;13:511-5

Duerr RH, Taylor KD, Brant SR, Rioux JD, Silverberg MS, Daly MJ, Steinhart AH, Abraham C, Regueiro M, Griffiths A, et al. A genome-wide association study identifies IL23R as an inflammatory bowel disease gene. Science 2006;314: 1461-3

Gao Y, Grassi F, Ryan MR, Terauchi M, Page K, Yang X, Weitzmann MN, Pacifici R. IFN-gamma stimulates osteoclast formation and bone loss in vivo via antigen-driven $\mathrm{T}$ cell activation. J Clin Invest 2007;117:122-32

Glas J, Seiderer J, Wetzke M, Konrad A, Torok HP, Schmechel S, Tonenchi L, Grassl C, Dambacher J, Pfennig $\mathrm{S}$, et al. rs1004819 is the main disease-associated IL23R variant in German Crohn's disease patients: combined analysis of IL23R, CARD15, and OCTN1/2 variants. PLoS ONE 2007;2:e819
Glueck CJ, Freiberg RA, Wang P. Role of thrombosis in osteonecrosis. Curr Hematol Rep 2003;2:417-22

Gold EW, Cangemi PJ. Incidence and pathogenesis of alcohol-induced osteonecrosis of the femoral head. Clin Orthop Relat Res 1979;143:222-6

Goldring SR, Goldring MB. Cytokines and skeletal physiology. Clin Orthop Relat Res 1996;324:13-23

Hedrick PW. Gametic disequilibrium measures: proceed with caution. Genetics 1987;117:331-41

Jones JP, Jr. Coagulopathies and osteonecrosis. Acta Orthop Belg 1999;65 Suppl 1:5-8

Kamel Mohamed SG, Sugiyama E, Shinoda K, Hounoki H, Taki H, Maruyama M, Miyahara T, Kobayashi M. Interleukin-4 inhibits RANKL-induced expression of NFATc1 and c-Fos: a possible mechanism for downregulation of osteoclastogenesis. Biochem Biophys Res Commun 2005;329:83945

Kamiya S, Nakamura C, Fukawa T, Ono K, Ohwaki T, Yoshimoto T, Wada S. Effects of IL-23 and IL-27 on osteoblasts and osteoclasts: inhibitory effects on osteoclast differentiation. J Bone Miner Metab 2007;25:277-85

Kerachian M, Harvey E, Cournoyer D, Chow T, Séguin C. Avascular Necrosis of the Femoral Head: Vascular Hypotheses. Endothelium 2006;13:237-44

Kim DJ, Park BL, Koh JM, Kim GS, Kim LH, Cheong HS, Shin HD, Hong JM, Kim TH, Park EK, Kim SY. Methionine synthase reductase polymorphisms are associated with serum osteocalcin levels in postmenopausal women. Exp Mol Med 2006;38:519-24

Kim TH, Hong JM, Park EK, Kim SY. Peroxisome Proliferator-activated Receptor-gamma Gene Polymorphisms are not associated with Osteonecrosis of the Femoral Head in the Korean Population. Mol Cells 2007;24:388-93

Lane NE. Therapy Insight: osteoporosis and osteonecrosis in systemic lupus erythematosus. Nat Clin Pract Rheumatol 2006;2:562-9

Migliaresi S, Picillo U, Ambrosone L, Di Palma G, Mallozzi M, Tesone ER, Tirri G. Avascular osteonecrosis in patients with SLE: relation to corticosteroid therapy and anticardiolipin antibodies. Lupus 1994;3:37-41

Mont MA, Jones LC, Einhorn TA, Hungerford DS, Reddi AH Osteonecrosis of the femoral head. Potential treatment with growth and differentiation factors. Clin Orthop Relat Res 1998; 355 Suppl:S314-35

Moreno JL, Kaczmarek M, Keegan AD, Tondravi M. IL-4 suppresses osteoclast development and mature osteoclast function by a STAT6-dependent mechanism: irreversible inhibition of the differentiation program activated by RANKL. Blood 2003;102:1078-86

Mundy GR. Regulation of bone formation by bone morphogenetic proteins and other growth factors. Clin Orthop Relat Res 1996;324:24-8

Murphy CA, Langrish CL, Chen Y, Blumenschein W, McClanahan T, Kastelein RA, Sedgwick JD, Cua DJ. 
Divergent pro- and antiinflammatory roles for IL-23 and IL-12 in joint autoimmune inflammation. J Exp Med 2003;198: 1951-7

Oppmann B, Lesley R, Blom B, Timans JC, Xu Y, Hunte B, Vega F, Yu N, Wang J, Singh K, et al. Novel p19 protein engages IL-12p40 to form a cytokine, IL-23, with biological activities similar as well as distinct from IL-12. Immunity 2000;13:715-25

Parham C, Chirica M, Timans J, Vaisberg E, Travis M, Cheung J, Pflanz S, Zhang R, Singh KP, Vega F, et al. A receptor for the heterodimeric cytokine IL-23 is composed of IL-12Rbeta1 and a novel cytokine receptor subunit, IL-23R. J Immunol 2002;168:5699-708

Qin ZS, Niu T, Liu JS. Partition-ligation-expectationmaximization algorithm for haplotype inference with singlenucleotide polymorphisms. Am J Hum Genet 2002;71: 1242-7

Raelson JV, Little RD, Ruether A, Fournier H, Paquin B, Van Eerdewegh P, Bradley WE, Croteau P, Nguyen-Huu Q, Segal $J$, et al. Genome-wide association study for Crohn's disease in the Quebec Founder Population identifies multiple validated disease loci. Proc Natl Acad Sci U S A 2007;1 04:14747-52

Rioux JD, Xavier RJ, Taylor KD, Silverberg MS, Goyette P, Huett A, Green T, Kuballa P, Barmada MM, Datta LW, et al.
Genome-wide association study identifies new susceptibility loci for Crohn disease and implicates autophagy in disease pathogenesis. Nat Genet 2007;39:596-604

Roberts RL, Gearry RB, Hollis-Moffatt JE, Miller AL, Reid J, Abkevich V, Timms KM, Gutin A, Lanchbury JS, Merriman TR, et al. IL23R R381Q and ATG16L1 T300A Are Strongly Associated With Crohn's Disease in a Study of New Zealand Caucasians With Inflammatory Bowel Disease. Am J Gastroenterol 2007;102:2754-61

Sanchez E, Rueda B, Callejas JL, Sabio JM, OrtegoCenteno N, Jimenez-Alonso J, Lopez-Nevot MA, Martin J. Analysis of interleukin-23 receptor (IL23R) gene polymorphisms in systemic lupus erythematosus. Tissue Antigens 2007;70:233-7

Sato K, Takayanagi H. Osteoclasts, rheumatoid arthritis, and osteoimmunology. Curr Opin Rheumatol 2006;18:419-26

Takayanagi H, Kim S, Taniguchi T. Signaling crosstalk between RANKL and interferons in osteoclast differentiation. Arthritis Res 2002;4 Suppl 3:S227-32

Tektonidou MG, Moutsopoulos HM. Immunologic factors in the pathogenesis of osteonecrosis. Orthop Clin North Am 2004;35:259-63

Weitzmann MN, Pacifici R. The role of T lymphocytes in bone metabolism. Immunol Rev 2005;208:154-68 